\title{
Implementasi Program Parenting Dalam Membangun Komunikasi Pengasuhan Anak Usia Dini (Penelitian Best Practice di TK Al-Jannah Kota Bandung)
}

\author{
Ani Setiani $^{1}$, Aliyah $^{2}$, Nugrihentine ${ }^{3}$, Rita Siti Mariam ${ }^{4}$ \\ Anggota Forum Guru Pendidikan AnakUsia Dini,Jawa Barat \\ Email: ani setiani@gmail.com, aliyah@gmail.com,nugrihentine@gmail.com, \\ ritasitimariam@gmail.com
}

\begin{abstract}
Abstrak
Pendidikan anak usia dini (PAUD), pada hakekatnya adalah pendidikan yang diselenggarakan dengan tujuan untuk memfasilitasi pertumbuhan dan perkembangan anak. Salah satu faktor penting penyelenggaraan PAUD adalah komunikasi yang efektif dan efisien antara pihak sekolah dengan orang tua. Program parenting di TK Al-Jannah selama Tahun pelajaran 2018/2019 terlaksana secara keseluruhan sesuai program yang direncanakan. Namun dampak dari kegiatan tersebut belum diteliti secara obyektif. Oleh karena itu, dilakukan penelitian yang bertujuan untuk mengetahui sejauh mana dampak program parenting di TK Al-Jannah terhadap pola asuh orang tua di rumah. Jenis penelitian yang disajikan adalah "Best Practice". Metode penelitian yang digunakan adalah metode penelitian kualitatif dengan tehnik pengumpulan data melalui studi dokumentasi, wawancara, dan observasi. Setelah dilakukan kajian dari berbagai unsur terlihat kecenderungan hasil akhir bahwa dengan Program Parenting yang telah dijalankan oleh TK AL Jannah melalui komunikasi yang efektif dilakukan baik oleh Kepala TK, pendidik dan orang tua, dapat meningkatkan kesamaan pemahaman orang tua dalam memberikan pola asuh yang baik kepada para putera puterinya hingga $90 \%$, capaian indicator 6 aspek pengembangan mencapai hasil $80 \%$ hingga $100 \%$.
\end{abstract}

Kata Kunci : Parenting; Komunikasi; Pengasuhan; PAUD

\begin{abstract}
Early childhood education (PAUD), in essence is education that is organized with the aim of facilitating children's growth and development. One important factor in the implementation of PAUD is effective and efficient communication between the school and parents. The parenting program at Al-Jannah Kindergarten during 2018/2019 was carried out as a whole according to the planned program. But the impact of these activities has not been studied objectively. Therefore, a study was conducted aimed at finding out the extent of the impact of the parenting program at Al-Jannah Kindergarten on parenting at home. The type of research presented is "Best Practice". The research method used is a qualitative research method with data collection techniques through the study of documentation, interviews, and observations. After a study of various elements shows the tendency of the final results that with the Parenting Program that has been run by TK AL Jannah through effective communication conducted both by the Head of Kindergarten, educators and parents, can increase the common understanding of parents in providing good parenting to the sons and daughters up to $90 \%$, achievement indicators 6 aspects of development achieved $80 \%$ to $100 \%$ results.
\end{abstract}

Keywords: Parenting; Communication; Nurturing; PAUD 


\section{PENDAHULUAN}

Anak usia dini adalah anak yang sedang berada dalam rentang usia 4-6 tahun yang merupakan sosok individu yang sedang berada dalam proses perkembangan. (PLPG Rayon 110: 2011). Pendidikan anak usia dini (PAUD), pada hakekatnya adalah pendidikan yang diselenggarakan dengan tujuan untuk memfasilitasi pertumbuhan dan perkembangan anak secara menyeluruh atau menekankan pada pengembangan seluruh aspek kepribadian anak. (Hildayani: 2017).

Salah satu faktor penting penyelenggaraan PAUD adalah komunikasi yang efektif dan efisien antara pihak sekolah dengan orang tua. Hildayani (2017) menyatakan bahwa komunikasi adalah proses pengiriman dan penerimaan informasi, ide, perasaan atau pesan (Uchyana,2003), maka strategi koumunikasi penting dikuasai oleh kepala sekolah untuk tercapainya tujuan yaitu ide atau program sekolah dapat diterima dan difahami dengan baik oleh orang tua, sehingga terjadi pihak sekolah dan orang tua dapat berjalan seiring sejalan. Dalam konteks kelompok, Lexicographer menyatakan bahwa komunikasi adalah upaya yang bertujuan untuk memberi dan meraih kebersamaan. Tujuan yang ingin diinginkan kedua belah pihak akan tercapai bila mereka berkomunikasi dan memiliki pemahaman yang selaras tentang informasi yang saling ditransfer (https://www.maxmanroe.com/vid/sosia 1/ pengertian-komunikasi.html).

Dalam hal ini Kementrian Pendidikan dan Kebudayaan telah memberikan petunjuk teknis pelaksanaan PAUD berbasis keluarga. Program kegiatan ini ditujukan kepada para orangtua atau anggota keluarga lain dalam rangka menyelaraskan pengetahuan dan keterampilan untuk melaksanakan perannya dalam peningkatan gizi dan kesehatan, perawatan, pengasuhan, pendidikan dan perlindungan di rumah sehingga anak dapat tumbuh dan berkembang secara optimal, sesuai usia dan tahap perkembangannya (Kemdikbud, 2012:2).

Di TK Al-Jannah Kecamatan Regol Kota Bandung, upaya membangun kerjasama pihak sekolah dan orang tua dilaksanakan melalui kegiatan keorangtuaan (parenting). Parenting adalah proses pembelajaran pengasuhan interaksi antara orang tua dan anak yang meliputi aktivitas memberi petunjuk, memberi makan,memberi pakaian, melindungi anak saat mereka tumbuh kembang. https://www.kompasiana.com.

Pengasuhan adalah kegiatan kompleks yang mencakup berbagai tingkah laku yang spesifik yang bekerja secara individu dan bersama-sama untuk mengasuh anak. Kegiatannya terdiri dari program inti, yaitu kegiatan rutin bulanan parenting umum dan parenting kelas serta penyelenggraan kegiatan yang diadakan oleh komite baik kegiatan sosial maupun kegiatan khusus yang melibatkan seluruh orang tua dan keluarga anak. Sedangkan kegiatan pendukung yaitu kewirausahaan pengadaan kantin komite serta kepanitiaan bersama pihak sekolah dan komite. Di samping itu Kepala Sekolah membangun komunikasi dengan misi "kekeluargaan", yaitu komunkasi yang dilakukan dalam bentuk formal maupun informal dalam upaya menyambungkan 
Implementasi Program Parenting Dalam Membangun Komunikasi Pengasuhan Anak Usia Dini

"kedekatan hati" demi tercapainya penerimaan ide/gagasan/program yang berlangsung lancar sesuai harapan.

\section{KAJIAN LITERATUR}

Program parenting di TK AlJannah selama Tahun pelajaran 2018/2019 terlaksana secara keseluruhan sesuai program yang direncanakan. Namun dampak dari kegiatan tersebut belum diteliti secara obyektif. Oleh karena itu, penelitian ini bertujuan untuk mengetahui sejauh mana dampak program parenting di TK Al-Jannah terhadap pola asuh orang tua di rumah. Dengan demikian peneliti memfokuskan paparan pada pelaksanaan dan dampak dari program inti keorangtuaan yaitu parenting umum dan parenting khusus yang dilaksanakan secara rutin di TK AlJannah. Menurut Bahri. (2014), proses komunikasi sama dengan proses pengasuhan dan pendidikan yang dilakukan secara formal oleh pendidik dan terdidik.

Adapun observasi kepada anak didik dilakukan melalui pendekatan historis kultural. Leontiev (1978) menyatakan fokus utama penelitian ini adalah studi kehidupan sehari-hari anak dalam konteks sosiokultural. Terutama dalam intitusi dimana anak-anak mendapatkan pengasuhan dan pembelajaran, yaitu keluarga, PAUD, dan sekolah. (Nusa Putra, Ninin Dwilestari : 2017). Dalam konteks ini, maka komunikasi yang harus dilakukan oleh para pendidik dijenjang PAUD harus mengenal lebih dekat secara psikologis. Mengingat upaya persuasif selama dekat dengan anak-anak maka fungsinya akan dominan,dimana ajakan, perhatian, arahan, pengasuhan serta upaya mengkomunikasikan semua faktor hidup anak-anak menjadi sentral dalam komunikasi ini. Kajian komunikasi untuk anak-anak banyak dikemukakan Litle John (2009), bahwa hal utama dalam keberhasilan proses komunikasi adalah bagaimana komunikator mampu melakukandan menunjukkan sikap,verbal dan gertural dalam bentuk mengajak. Dalam hal ini proses persuasive sangat dibutuhkan dalam proses pengasuhan anak, diantaranya dijelaskan oleh Hastasari, C, dkk. (2015) bahwa pola pengasuhan anak akan berjalan seiring dengan proses berbicara dan bersikap tutur tindak antara pengasuh dengan yang diasuh.

\section{METODOLOGI}

Penelitian ini disajikan sebagai "Best Practice", yaitu sebuah karya tulis yang menceritakan pengalaman terbaik dalam menyelesaikan sebuah permasalahan yang dihadapi oleh pendidik dan tenaga kependidikan sehingga mampu memperbaiki mutu layanan pendidikan dan pembelajaran https://www.kompasiana.com. Dalam hal ini, peneliti mendeskripsikan program keorangtuaan di TK Al-Jannah beserta dampak dan hasilnya terhadap ketercapaian perkembangan anak.

Metode penelitian yang digunakan adalah metode penelitian kualitatif. Metode ini dipilih karena peneliti bermaksud untuk mengetahui program parenting di TK Al-Jannah, dilakukan pada setting alami tanpa manipulasi, menggambarkan dan menginterpretasikan subyek apa adanya dan analisa dilakukan secara induktif. Hal itu didasarkan pada ciri-ciri penelitian kualitatif yang dikemukakan 
oleh Sugiyono (2005: 2) dengan mengutip pendapat Bogdan dan Bilken (1982) Lebih lanjut Penelitian ini mendeskripsikan dan menganalisisfenomena-fenomena, peristiwa, aktivitas sosial secara alamiah, sikap, kepercayaan, presepsi, pemikiran orang secara individual maupun kelompok. Beberapa deskripsi digunakan untuk menemukan prinsipprinsip dan penjelasan yang mengarah kepada penyimpulan. (Sa'ud: 2007).

Subyek penelitian ini adalah kepala TK, pendidik dan orang tua TK Al-Jannah. Tehnik pengumpulan data dilakukan melalui kegiatan observasi, studi dokumentasi dan wawancara baik terhadap sumber data primer (semua stakeholder sekolah) maupun sumber data sekunder yaitu pihak luar yang berhubungan dengan sekolah. Wawancara dilakukan secara terstruktur yaitu pertanyaan yang disiapkan alternatif jawabannya, semistruktur yaitu pihak yang diajak wawancara diminta pendapat dan ide-idenya, serta tak terstruktur yaitu tidak digunakan pedoman pertanyaan terstruktur, hanya garis besarnya untuk mendapatkan opini sedalam-dalamnya (Sugiyono, 2005:6264).

Analisis terhadap hasil pengumpulan data dilakukan secara induktif, yaitu mendeskripsikan data dengan memberikan makna terhadap isi, kemudian dilakukan penafsiran rasional berdasarkan teori yang ada dan hubungan sebab akibat antar peristiwa atau kondisi dan dibuat kesimpulan. Peneliti membiarkan permasalahanpermasalahan yang muncul dari data atau dibiarkan terbuka untuk interpretasi. Data dihimpun dengan pengamatan yang seksama, mencakup deskripsi dalam konteks yang mendetail disertai catatan- catatan hasil wawancara yang mendalam, serta hasil analisis dokumen dan catatan-catatan.

\section{HASIL DAN PEMBAHASAN}

Program keorangtuaan di TK AlJannah terdiri dari 2 kategori. Pertama, program inti mencakup : (1) Parenting umum yang dikemas dalam bentuk pengajian rutin bulanan setiap Jumat ke 1 di sesi pagi, peserta seluruh orang tua dengan materi tentang pendidikan, gizi dan kesehatan, keagamaan, perlindungan anak, serta pola asuh dan bimbingan di rumah (2) Parenting khusus kegatan parenting yang disampaikan oleh guru di kelas yang membahas tentang satu topik bahasan dan diskusi perkembangan anak dan tindak lanjut pola asuh di rumah. Kedua, program pendukung yaitu (1) Pembentukan komite TK; Penyediaan tempat untuk kewirausahaan berupa kantin komite; (3) Pemberdayaan komite : kegiatan sosial menjalin silaturahmi (menengok anak sakit dan ibu melahirkan), penyelengaraan peringatan HUT RI dan Hari Ibu sebagai Family Day, menjadi panitia qurban dan panggung perpisahan, mengkoordinir orang tua dalam mendukung kegiatan fied trip, serta pengadaan bingkisan anak akhir tahun pelajaran serta (4) Pengadaan menu makan hari jumat oleh orang tua secara bergiliran sebagai tambahan gizi seimbang bagi anak (5). Pelatihan guru yang berkenaan dengan kompetensi sosial dan kepribadian melalui pelatihan EI (Emotional Intelligent) serta pembinaan kepegawaian yang berimbas kepada peningkatan kemampuan komunikasi guru terhadap orang tua. Teknis komunikasi yang dibangun dalam 
Implementasi Program Parenting Dalam Membangun Komunikasi Pengasuhan Anak Usia Dini

keseluruhan programnya melalui jalur formal (parenting) dan informal yaitu (1) Whats App grup (2) Home visit dan (3) komunikasi langsung selesai guru bertugas apabila diperlukan. Temuan ini sesuai dengan kajian-kajian dari Azis, A. (2012) tentang proses parenting.

Dalam teknik pengumpulan data peneliti melakukan studi dokumentasi yang terdiri dari (1) Dokumentasi yang berkaitan dengan parenting dan pembinaan guru : jadwal, materi, surat undangan, notulen, daftar hadir, foto kegiatan (2) Administrasi guru berupa penilaian perkembangan anak dalam bentuk ceklis, jurnal harian, catatan anekdot, wawancara, unjuk kerja, portoflio hasil karya, serta kompilasi penilaian bulanan dan analisa evaluasi (3) Dokumentasi kegiatan khusus orang tua (lomba orang tua, pemberian menu makan, home visit, kepanitiaan bersama pihak sekolah) baik berupa foto, maupun jadwal kegiatan. Adapun wawancara dilakukan kepada sumber primer yaitu kepala TK, guru, dan orang tua siswa serta sumber sekunder yaitu pengawas TK dari Dinas Pendidikan. Adapun observasi kepada anak didik dilakukan pada bulan Mei 2019.

Data yang didapatkan dari studi dokumentasi, wawancara dan observasi sebagai berikut: Pertama, pelaksanaan program keorangtuaan inti (parenting umum dan parenting kelas) konsisten dijalankan pihak sekolah sebanyak $10 \mathrm{x}$ pertemuan selama Tahun Pelajaran 2018/2019. Hal ini menunjukkan TK AlJannah selaku lembaga melaksanakan program PAUD berbasis keluarga (Kemdikbud, 2012:2).

Kedua, kesamaan pemahaman orang tua tentang pola pengasuhan terwujud, $90 \%$ menyatakan memahami dan siap melaksanakan, $10 \%$ memahami namun belum sepenuhnya siap melaksanakan secara keseluruhan karena berbagai kendala. Hal ini menunjukkan pola komunikasi yang dibangun untuk menyampaikan ide dan gagasan (program sekolah) efektif dilakukan oleh pihak sekolah (Hildayani :2017).

Ketiga, ketercapaian indikator

\begin{tabular}{|c|c|c|c|c|c|c|c|c|}
\hline \multirow{2}{*}{ No } & \multirow{2}{*}{ Kel } & \multirow{2}{*}{ Kategori } & \multicolumn{6}{|c|}{ Hasil Penilaian (\%) } \\
\cline { 4 - 9 } & & $\begin{array}{c}\text { Moral } \\
\text { Agama }\end{array}$ & Bahasa & Kognitif & $\begin{array}{c}\text { Fisik } \\
\text { Motorik }\end{array}$ & $\begin{array}{c}\text { Sosial } \\
\text { Emosional }\end{array}$ & Seni \\
\hline \multirow{2}{*}{1} & \multirow{2}{*}{$\mathrm{A}$} & MB & 10 & 5 & 20 & 20 & 5 & 30 \\
\cline { 3 - 9 } & & BSH & 70 & 80 & 70 & 80 & 70 & 70 \\
\cline { 3 - 9 } & & BSB & 20 & 15 & 10 & 20 & 25 & - \\
\hline \multirow{2}{*}{2} & \multirow{2}{*}{ B } & MB & 20 & - & 10 & - & - & - \\
\cline { 3 - 9 } & & BSH & 70 & 60 & 70 & 50 & 30 & 70 \\
\cline { 3 - 9 } & & BSB & 10 & 40 & 10 & 50 & 70 & 20 \\
\hline
\end{tabular}

pencapaian perkembangan anak baik dari pencapaian kompetensi dasar dan STTPA (Standar Pencapaian Perkembangan Anak) meningkat secara berkala. Hal tersebut dapat dilihat dalam administrasi penilaian guru berupa kompilasi penilaian bulanan, perangkat jenis-jenis evaluasi, analisa evaluasi serta hasil observasi langsung. Penilaian dituangkan dalam empat kategori BSB (Berkembang Sangat Baik), BSH (Berkembang Sesuai Harapan) dan MB (Mulai Bekembang) dan BB Belum Berkembang). Hasil yang didapatkan sebagai berikut :

Tabel .1 Pencapaian Seluruh Lingkup Perkembangan Kelompok A dan B

Perolehan perkembangan $\mathrm{BSH}$ (Berkembang Sanga Baik) dan BSB (Berkembang Sesuai Harapan) sebagai indikator keberhasilan pembelajaran digambarkan dalam grafik sebagai berikut :

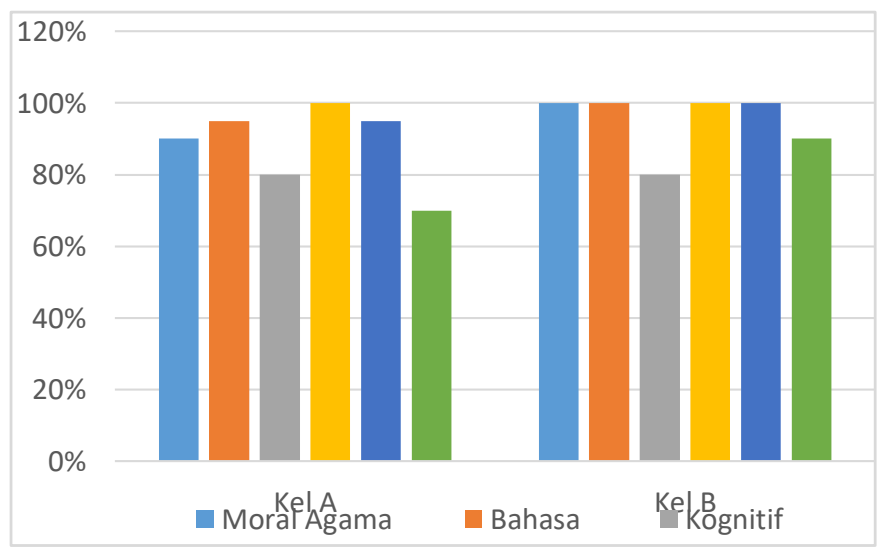


Grafik.1 Pencapaian Perkembangan BSH dan BSB Kelompok A dan B

$$
\text { Dari data di atas dapat }
$$
disimpulkan bahwa siswa TK Al-Jannah pada umumnya mencapai perkembangan yang diharapkan dengan kategori Berkembang sesuai harapan dan berkembang sangat baik dalam tiap lingkup perkembangannya. Dengan demikian fungsi lembaga PAUD mengembangkan seluruh aspek perkembangan telah tercapai (Hildayani: 2017). Demikian juga ditegaskan oleh Astrida (2014), bahwa aspek pola asuh orang tua sangat butuh upaya pengkondisian di lapangan yang berbeda. Hal ini diraih berkat kerjasama yang sinergis antara semua stakehoder sekolah (kepala TK, guru, orang tua) serta pengawas sekolah yang senantiasa memberikan bimbingan dan arahan kepada pihak sekolah dalam melaksanakan keseluruhan programnya, Hibana. (2002.

Keempat, berdasarkan wawancara dengan orang tua dan guru, didapatkan hasil bahwa dengan adanya jalur komunikasi formal (parenting kelas), WA grup, facebook serta website sekolah, kedua pihak merasa semakin mudah berkomunikasi serta dapat mengakses berbagai informasi yang berkenaan dengan kegiatan anak dan perkembangannya, sehingga kerjasama keduanya dalam mencapai tujuan bersama yaitu berkembangnya anak secara optimal dapat tercapai (Lexicographer dalam https://www.maxmanroe.com/vid/sosial /pengertian-komunikasi.html) . Semua komunikasi ini dibangun dengan pola komunikasi yang "hangat" dari guru, sehingga tujuan sekolah membangun komunikasi secara "kekeluargaan" terwujud dengan lancar. Temuan memperkuat pendapat dari Sudjana, D. (2010) tentang penyelenggaraan Pedidikan Masyarakat dalam konteks PKBM untuk anak usia dini.

\section{SIMPULAN DAN REKOMENDASI}

$\begin{array}{rrr}\text { Penelitian } & \text { yang } & \text { berjudul } \\ \text { "Implementasi } & \text { Program } & \text { Parenting }\end{array}$ Dalam membangun Komunikasi Pengasuhan Anak Usia Dini" ini menggunakan metode kualitatif dengan tehnik pengumpulan data melalui studi dokumentasi, wawancara, dan observasi. Setelah dilakukan kajian dari berbagai unsur terlihat kecenderungan hasil akhir bahwa dengan Program Parenting yang telah dijalankan oleh TK AL Jannah melalui komunikasi yang efektif dilakukan baik oleh Kepala TK, pendidik dan orang tua, dapat meningkatkan kesamaan pemahaman orang tua dalam memberikan pola asuh yang baik kepada para putera puterinya hingga $90 \%$. Ketercapaian indikator Pencapaian perkembangan anak dari pencapaian Kompetensi Dasar dan STPPA melalui bidang pengembangan moral agama 95\% untuk kelompok A dan 100\% untuk kelompok B, bahasa $98 \%$ untuk kelompok A dan $100 \%$ untuk kelompok B, kognitif $80 \%$ untuk kelompok A dan $80 \%$ untuk kelompok B, fisik motorik $100 \%$ untuk kelompok A dan 100\% untuk kelompok B, Sosial emosional 98\% untuk kelompok A dan $100 \%$ untuk 
Implementasi Program Parenting Dalam Membangun Komunikasi Pengasuhan Anak Usia Dini

kelompok B, Seni $75 \%$ untuk kelompok A dan 90\% untuk Kelompok B. Saran dari penulis adalah agar TK AL Jannah tetap mempertahankan serta meningkatkan komunikasi yang efektif antara kepala sekolah pendidik dan orang tua murid.

\section{DAFTAR PUSTAKA}

Astrida (2014). Peran dan Fungsi Orang Tua dalam Mengembangkan Kecerdasan Emosional Anak. [Online]. Tersedia: sumsel.kemenag.go.id/file/file/BA NYUASIN/pfy1341188835.pdf. [1 Oktober 2014]

Azis, A. (2012). Parenting. [Online]. Tersedia: http://aliaziz.gurusertifikasi .org/ 2012 /05 /09/ parenting/.[1 Oktober 2014].

Effendy, O., U. (2003). Ilmu Komunikasi Teori dan Praktek. Bandung: Remaja Rosdakarya

Hildayani, R. (2009). Penanganan Anak Berkelainan. Jakarta: Universitas Terbuka

Djamarah, S., Bahri. (2014). Pola Asuh Orang Tua dan Komunikasi dalam Keluarga. Jakarta: PT Rineka Cipta.

Hastasari, C, dkk. (2015). Pola Asuh Balita Ibu-Ibu Kelompok Sasaran Pada Program Kegiatan Bina Keluarga Balita Usia 0-12 Bulan Dusun Gandekan Kartasura. INFORMASI Kajian Ilmu Komunikasi Volume 45. Nomor 1. Juni 2015.
Hibana. (2002). Konsep Dasar Pendidikan Anak Usia Dini. Yogyakarta: PGTKI Press.

John, L.(2009). Persuasive Communication. NewJersey: Prentice-Hall.

Sudjana, D. (2010). Manajemen Program Pendidikan: untuk Pendidikan Nonformal dan Perkembangan Sumber Daya Manusia. Bandung: Falah Production

Sugiyono. (2013). Metode Penelitian Manajemen. Bandung: Alfabeta

Kementrian Pendidikan dan Kebudayaan. (2012). Model Pelaksanaan Program Pendidikan Keorangtuaan di Lembaga Pendidikan Anak Usia Dini. Jakarta: Kemendikbud Kementrian Pendidikan Nasional. (2011).

Kemendiknas.(201). Petunjuk Teknis Orientasi Teknis Peningkatan Pemahaman Program Penguatan PAUD Berbasis Keluarga (Parenting). Jakarta: Kemendiknas Tahun 2015. https://www.maxmanroe.com/vid/sosial /pengertian-komunikasi.html https://www.kompasiana.com. https://www.maxmanroe.com/vid/sosial /pengertian-komunikasi.html 